\title{
Zen-like Simplicity is Hard Work, and Other Secrets I Learned from Peter Swann
}

Ondrej L. Krivanek ${ }^{1}$

${ }^{1}$ Nion Co., 11511 NE $118^{\text {th }}$ St., Kirkland, WA 98034, USA

Peter Roland Swann was born in Williton in Somerset UK a few years before World War II. Wartime rationing was a fact of life when he was growing up, and there were other privations too. Their effect on Peter seems to have been to make him uncommonly resourceful and imaginative in transforming whatever life provided him with into wonderful new things.

This talent served him particularly well when he finished his $\mathrm{Ph}$. D. studies at Cambridge, UK, and joined the research staff at the US Steel Research Center in Monroeville PA, USA. Unraveling the mysteries of dislocations and other defects in metals by imaging them in the newly available electron microscopes was a hot topic back then. Peter developed a double-tilt sample holder for a Siemens Elmiskop I electron microscope [1], which allowed crystals to be imaged in the precise orientation needed for $\mathbf{g . b}$ contrast of dislocations ( $\mathbf{g}=$ chosen reflection, $\mathbf{b}=$ Burgers vector). This was a major step on a career path that Peter honed to perfection over the years: developing new capabilities for electron microscopes, preferably in areas that had hardly been touched.

The new holder also led to the founding of Gatan. Siemens liked the design so much that they approached Peter about supplying them with ten double-tilt holders. Peter's brother Rex, a mechanical engineer, was living nearby in Pittsburgh, and together they decided to start a business manufacturing the holders. They purchased a lathe and a milling machine at Sears, and sought legal help to incorporate the business. Peter was studying German at the time and thought that "getan", the past participle of "tun" (to do), which means "done, finished, completed" would be a great name for the business, with a nice ring and a good message. However, a typo in a legal document resulted in the name being spelled "Gatan". Peter and Rex thought that this name sounded good too. Hating unnecessary paperwork, they incorporated the company under the name Gatan on April 1, 1964.

Peter became a Reader (and then Professor) at Imperial College London a few months after Gatan was founded. Spending his summers in Pittsburgh, he kept up a steady stream of designs for Gatan to manufacture, such as environmental chambers and heating holders for high-voltage electron microscopes. He also made major advances in corrosion science [2]. In 1976, he switched to working at Gatan full-time, and the range of new designs he introduced grew considerably.

Keep It Small and Simple (KISS) was a key dictum of Peter's. My first collaboration with him, 16 years after Gatan was founded, involved redesigning a serial detection electron energy-loss spectrometer I had built at UC Berkeley. Peter did the mechanical design, and "KISS" very much stood out. Where I had used some 20 screws to hold the spectrometer's prism and detection chamber together, Peter used just 6. Where I did not worry much about the manufacturing steps that would need to be undertaken, Peter carefully optimized the design so that most parts could be made in a few steps on a lathe. Working with Peter was very inspirational, and I joined Gatan full-time (on April 1, 1985) after Peter established the Gatan R\&D facility in California.

This M\&M session is focusing on environmental microscopy, to which Peter made major contributions. 
Other products he designed or co-designed that enabled key progress to be made in various fields of research included cryo-transfer holders for cryo-microscopy, ion mills and mechanical polishing equipment for general specimen preparation, TV-rate cameras for EM imaging, energy-loss spectrometers for analysis, and an early focused ion beam (FIB) machining system (called PIMS precision ion milling system) for precision sample preparation.

Blaise Pascal's famous excuse: "I have made [this letter] longer than usual because I have not had the time to make it shorter" was not for Peter - he took whatever time was necessary for Zen-like purity of design. Long hours were needed to achieve the purity, and Peter once calculated that out of the 168 hours in each week, some 50 were needed for sleep, 20 for general upkeep, eating and recreation, and the rest - roughly 100 hours per week - could be spent on work. This was not popular with Peter's family and friends, but we all had the greatest respect for his work ethic and dedication. And we loved the amusing moments: Peter had a sharp wit and a wonderful sense of humor, and nobody ever got bored in his company.

Peter's focus on the essential and great sense of humor made his scientific talks captivating and fun. His last talk, as far as I know, was given at Carnegie Mellon University in Pittsburgh in 2011. Fig. 1 shows the talk's last slide: a revolutionary new sample holder for a high voltage electron microscope. The surprised onlookers should have known better. Peter was always an original thinker/doer, and he excelled at finding the humor in any situation. Much like a Zen master would.

\section{References:}

[1] G.V. Patser and P.R. Swann, J. Sci Instr. 39 (1962) p. 58.

[2] P.R. Swann in "Mats Science and Engineering" ed. M. McLean, (Maney Publishing, London, 2002) p. 53.

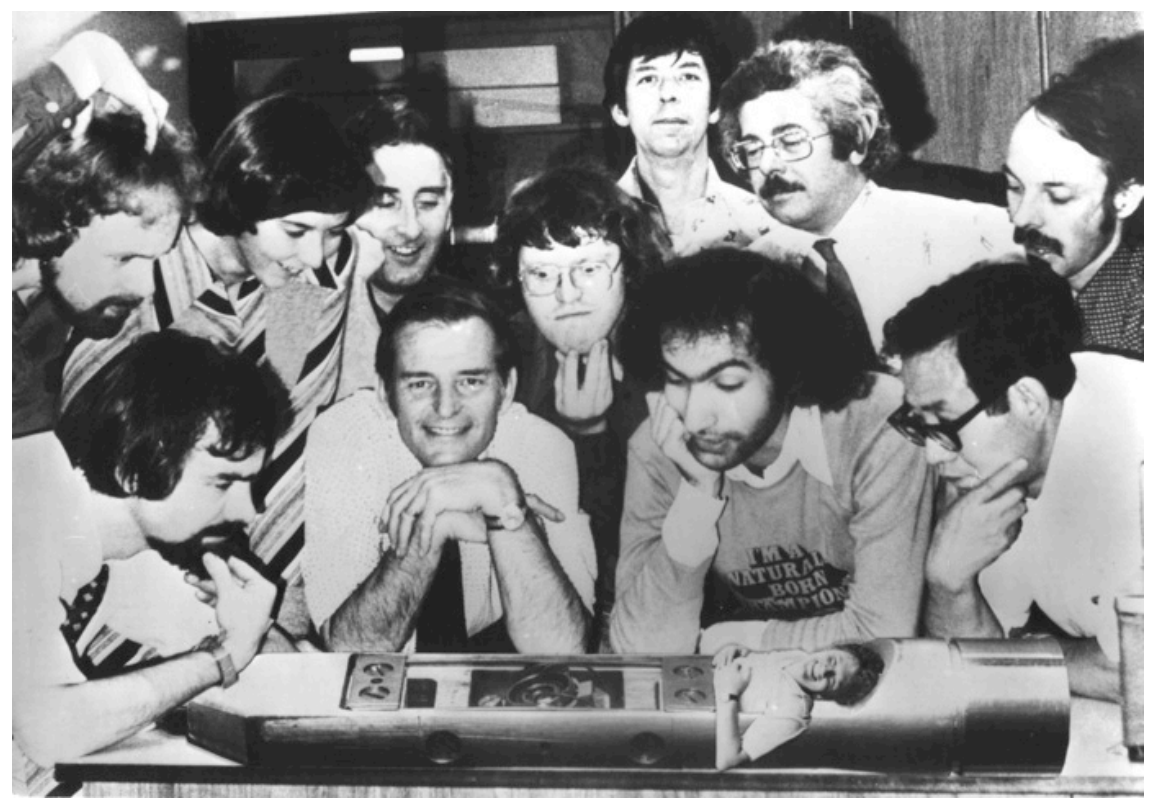

Figure 1. A side-entry sample-heating holder designed by Peter Swann for a high voltage electron microscope equipped with his environmental chamber. The EM research group at Imperial College, London, surrounds the holder, Peter himself is clamped in it. 